\title{
Afferent Input Is Necessary for Seasonal Growth and Maintenance of Adult Avian Song Control Circuits
}

\author{
Eliot A. Brenowitz and Karin Lent \\ Departments of Psychology and Zoology and Virginia Merrill Bloedel Hearing Research Center, University of Washington, \\ Seattle, Washington 98195-1525
}

The neural circuits that regulate song behavior in adult songbirds undergo pronounced seasonal changes in morphology, primarily in response to changes in plasma testosterone (T). Most song nuclei have T receptors. We asked whether seasonal growth and maintenance of nuclei within these circuits are direct responses to the effects of $\mathrm{T}$ or its metabolites or are mediated indirectly via the effects of $T$ on afferent nuclei. Photosensitive white-crowned sparrows were exposed to one of three treatments. (1) The neostriatal nucleus HVc (also known as the "high vocal center") was lesioned unilaterally, and the birds were exposed to long-day (LD) photoperiods and breeding levels of $\mathrm{T}$ for $30 \mathrm{~d}$. (2) Birds were exposed to LD plus T $(\mathrm{LD}+\mathrm{T})$ for $30 \mathrm{~d}$; then HVc was lesioned, and the birds were killed after an additional $30 \mathrm{~d}$ exposure to LD+T. (3) HVc was lesioned, and the sparrows were housed on short-day (SD) photoperiods in the absence of $\mathrm{T}$ treatment for $30 \mathrm{~d}$. In both $\mathrm{LD}+\mathrm{T}$ groups, the direct efferent targets of $\mathrm{HVc}$, the robust nucleus of the archistriatum (RA) and area $X$, were smaller ipsilateral to the lesion. The lesion did not prevent growth of the hypoglossal motor nucleus, which does not receive direct afferent input from HVc. RA and area $X$ were also smaller ipsilateral to the lesion in the SD birds. These results indicate that afferent input is required both for the growth of adult song circuits in response to typical breeding photoperiod and hormone conditions and for the maintenance of efferent nuclei in either their regressed or enlarged states.

Key words: afferent; bird; birdsong; plasticity; season; songbird; song; song system; testosterone; trophic; white-crowned sparrow
Seasonal changes in the morphology of adult brain nuclei occur in every vertebrate class (Tramontin and Brenowitz, 2000). The nuclei that control song learning and production in birds are easily identified, and their connectivity is well established (Fig. 1) (for review, see Bottjer and Johnson, 1997; Wild, 1997). The avian song control system has emerged as a leading model for studying seasonal plasticity in the brain. There is pronounced seasonal plasticity in the morphology of nuclei in the song control system (for review, see Tramontin and Brenowitz, 2000). These seasonal changes in the song system are primarily regulated by changes in plasma levels of testosterone $(\mathrm{T})$ that are correlated with changes in photoperiod (Gulledge and Deviche, 1997; Smith et al., 1997a; Ball, 2000). Most nuclei within the song control circuits have receptors for androgenic hormones (Fig. 1) (for review, see Bottjer and Johnson, 1997; Schlinger, 1997). We do not yet know, however, whether seasonal growth of different nuclei within these circuits is a direct response to the effects of $\mathrm{T}$ or its metabolites or is mediated indirectly via the effects of $\mathrm{T}$ on afferent nuclei. This study was designed to test these alternative hypotheses.

Growth of HVc (Fig. 1, HVC) in response to breeding season cues precedes that of its direct efferent target nuclei RA and area $\mathrm{X}$ in song sparrows (Melospiza melodia) and Gambel's white-

\footnotetext{
Received Aug. 29, 2000; revised Dec. 20, 2000; accepted Jan. 17, 2001.

This work was supported by National Institutes of Health Grant MH 53032 and the Virginia Merrill Bloedel Hearing Research Center. We thank Troy Smith, Tony Tramontin, Kira Wennstrom, and two anonymous referees for valuable comments on this manuscript.

Correspondence should be addressed to Dr. Eliot A. Brenowitz, Department of Psychology, Box 351525, University of Washington, Seattle, WA 98195-1525. E-mail: eliotb@u.washington.edu.

Copyright (C) 2001 Society for Neuroscience $\quad 0270-6474 / 01 / 212320-10 \$ 15.00 / 0$
}

crowned sparrows (GWCS; Zonotrichia leucophrys gambelii) (Smith et al., 1997c; Tramontin et al., 2000). These observations led to the hypothesis that afferent input from $\mathrm{HVc}$ is required for the growth of RA and area X. Afferent input is important in the development and maintenance of diverse neural systems (LeviMontalcini, 1949; Clarke, 1985; Beyer and Feder, 1987; Furber et al., 1987; Rubel et al., 1990). In the birdsong system, depriving RA and area X of afferent input in juvenile zebra finches (Taenopygia guttata) prevents these nuclei from growing to their normal size in males (Akutagawa and Konishi, 1994; Johnson and Bottjer, 1994) and blocks the masculinization of these regions in females that is caused by early treatment with estradiol (Herrmann and Arnold, 1991). If plasticity in adult song circuits exploits mechanisms similar to those of juvenile development (Tramontin and Brenowitz, 2000), then we predict that depriving adult song nuclei of their afferent input would prevent their growth in response to seasonal-like cues.

An alternative mechanism for seasonal plasticity is that $\mathrm{T}$ or its metabolites act directly on different song nuclei that contain steroid receptors. Steroid hormones such as $\mathrm{T}$ can have direct trophic effects on brain nuclei (Perez and Kelley, 1996, 1997; Kay et al., 1999). Hormones may also act on the efferent targets of neurons that can then provide retrograde trophic support to the neurons (Kelley, 1986; Fishman et al., 1990; Oppenheim, 1991; Fishman and Breedlove, 1992; Lohmann and Gahr, 2000). In either scenario, afferent input may not be required for the growth and maintenance of brain nuclei. A prediction of either model is that we would observe growth of adult song nuclei that contain steroid receptors in response to breeding levels of $\mathrm{T}$, even in the absence of afferent input.

In this study we investigated whether afferent input from $\mathrm{HVc}$ 


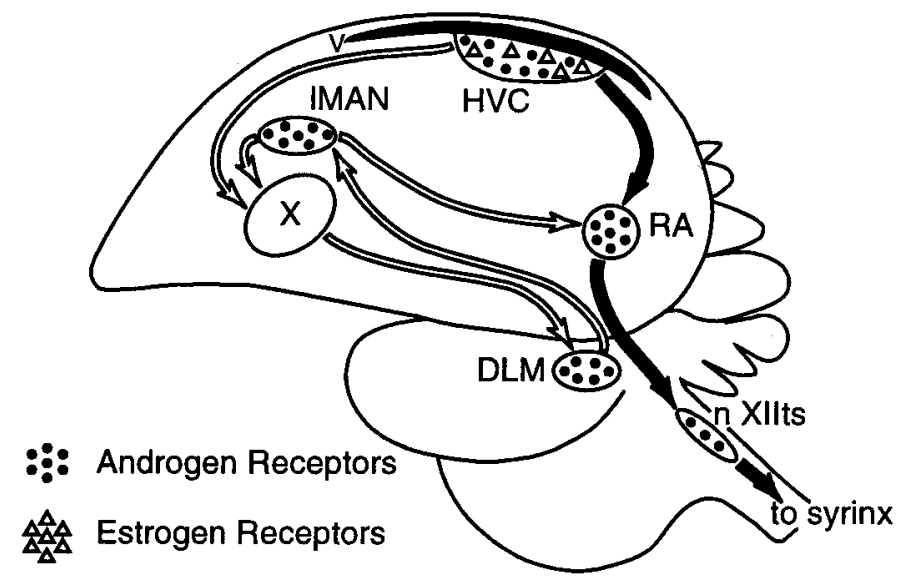

Figure 1. Simplified schematic sagittal view of the avian song control system showing the distribution of steroid receptors. Black arrows connect nuclei in the main descending motor circuit, and white arrows connect nuclei in the anterior forebrain circuit. $D L M$, Dorsolateral nucleus of the medial thalamus; $I M A N$, lateral portion of the magnocellular nucleus of the anterior neostriatum; $n X I I t s$, the tracheosyringeal portion of the hypoglossal nucleus; $R A$, the robust nucleus of the archistriatum; syrinx, vocal production organ; $V$, lateral ventricle; $X$, area $\mathrm{X}$ of the parolfactory lobe.

is necessary for the maintenance and seasonal-like growth of efferent song nuclei in adult male GWCS; this nucleus provides input to both the motor and anterior forebrain circuits (Fig. 1). In white-crowned sparrows there are pronounced changes in the volumes of song nuclei and neuronal attributes of these nuclei in response to seasonal changes in photoperiod and plasma $\mathrm{T}$, both in the wild and in the laboratory (for review, see Tramontin et al., 2000). We found that afferent input is required for both the maintenance and seasonal-like growth of telencephalic song nuclei.

\section{MATERIALS AND METHODS}

Collection of birds and experimental treatments. We captured 24 adult male GWCS in eastern Washington during their postbreeding season migration in September and October 1998. All birds were housed indoors for 12 weeks on short days (SD; $8 \mathrm{hr}$ light) before the start of the experiment to ensure that their reproductive systems were regressed but sensitive to the stimulating effects of breeding photoperiods (i.e., they were photosensitive). White-crowned sparrows kept on SD indefinitely maintain regressed testes, basal or nondetectable levels of circulating $\mathrm{T}$, and regressed song control nuclei that are typical of the nonbreeding season (Middleton, 1965; Sansum and King, 1976; Smith et al., 1995, 1997b).

The birds were placed in three different treatment groups. (1) SD group. In eight birds, HVc was lesioned unilaterally as described below. On the day after surgery each bird received an empty SILASTIC implant as a control for the $\mathrm{T}$ pellets implanted in the other two groups (see below). These birds remained on SD for $30 \mathrm{~d}$ after the lesion and were then killed as described below. (2) Long-day (LD) plus $\mathrm{T}$ (LD+T) growth ("growth") group. We lesioned HVc unilaterally in nine birds while they were housed on SD and photoshifted them that night to LD (20 hr of light), typical of what they would experience on their Alaskan breeding grounds. On the day after surgery we implanted each bird with a SILASTIC capsule $(1.47 \mathrm{~mm}$ inner diameter $\times 1.96 \mathrm{~mm}$ outer diameter) containing $12 \mathrm{~mm}$ of crystalline $\mathrm{T}$ to elevate rapidly plasma concentrations of this hormone into the range typical of wild breeding birds (4-10 ng/ml) (Wingfield and Farner, 1978). We killed these birds $30 \mathrm{~d}$ after their initial exposure to $\mathrm{LD}+\mathrm{T}$. This time period is adequate for full seasonal growth of the song nuclei (Smith et al., 1995, 1997a; Tramontin et al., 2000). (3) LD+T maintenance ("maintenance") group. Seven birds were shifted overnight from SD to LD and implanted with the same dose of $\mathrm{T}$ that the growth birds received. After $30 \mathrm{~d}$ on $\mathrm{LD}+\mathrm{T}$ we lesioned HVc unilaterally. We replaced each bird's T implant on the day of surgery to ensure that it maintained high circulating $\mathrm{T}$ levels. We killed the birds in this group $30 \mathrm{~d}$ after the $\mathrm{HVc}$ lesion surgery and $60 \mathrm{~d}$ after their initial exposure to $\mathrm{LD}+\mathrm{T}$.

Each treatment group was designed to address a different question regarding the role of afferent input and direct trophic effects of $\mathrm{T}$ in the song system. The SD group would indicate whether afferent input from $\mathrm{HVc}$ is necessary for the maintenance of RA, area $\mathrm{X}$, and other song nuclei even in their regressed, nonbreeding state. The growth birds would show whether afferent input from $\mathrm{HVc}$ is necessary for the initial growth of these song regions in response to breeding conditions. The maintenance group would determine whether afferent input from $\mathrm{HVc}$ is required for the maintenance of these nuclei after they have grown during the preceding $30 \mathrm{~d}$ of $\mathrm{LD}+\mathrm{T}$.

The song nuclei of male GWCS will grow in response to spring environmental conditions in the field or to gradual increases in photoperiod in the laboratory, without T implants (Soma et al., 1998; Tramontin et al., 1999). Increases in circulating $\mathrm{T}$ are primarily responsible for this growth (Gulledge and Deviche, 1997; Smith et al., 1997a; Ball, 2000). Plasma T levels increase slowly over several days in both the field and laboratory, however, and the timing of this increase varies considerably between individual birds (Wingfield and Farner, 1978; Tramontin et al., 1999). We were concerned that this variability might obscure the effects of the HVc lesions. To control for this variability, we shifted all birds in the growth group to LD overnight after the lesion surgery and implanted them with $\mathrm{T}$ pellets that rapidly produced plasma levels of $\mathrm{T}$ within or above the physiological range. This treatment should bias against observing an effect of $\mathrm{HVc}$ lesions on the growth and maintenance of RA and area $\mathrm{X}$ if $\mathrm{T}$ does act directly on these nuclei.

Surgical procedure. $\mathrm{HVc}$ was lesioned unilaterally with $1 \%$ racemic NMA in PBS, pH 7.4. We lesioned both the rostral main corpus and caudomedial extension of $\mathrm{HVc}$ at the following stereotaxic coordinates (relative to the intersection of the midsagittal and transverse sinuses and the brain surface): anteroposterior $=0.0 \mathrm{~mm}$ (rostral) and $-0.3 \mathrm{~mm}$ (caudal); mediolateral $=1.8 \mathrm{~mm}$ (caudal) and $2.8 \mathrm{~mm}$ (rostral); and depth $=0.5$ and $0.7 \mathrm{~mm}$ (rostral) and $0.65 \mathrm{~mm}$ (caudal). We injected 800 $\mathrm{nl}$ of NMA at each depth for the rostral site and $800 \mathrm{nl}$ at the single caudal site using a customized pressure delivery system. This system consisted of Tygon tubing connected to the outflow of a Gast vacuum pressure pump, with a T-shaped connector inserted in the pathway to allow us to regulate the flow of air to a calibrated micropipette for the delivery of NMA. We alternated lesions between the left and right $\mathrm{HVc}$ in successive birds in each group.

Hormone assay. We collected $300 \mu \mathrm{l}$ of whole blood into heparinized microcentrifuge tubes by puncturing the alar vein. Samples were collected from each male the day before he received SILASTIC implants and at 2 and 4 weeks after the implant. The SD and growth birds were killed at 4 weeks. T pellets were replaced in the maintenance birds at 4 weeks, and blood samples were collected 2 weeks later ( 6 weeks after the start of the experiment) and then again just before death at 7 weeks after the start of the experiment. Each blood sample was immediately centrifuged, and the plasma was removed and stored at $-20^{\circ} \mathrm{C}$ until assay. We measured $\mathrm{T}$ in the plasma by radioimmunoassay using the Coat-A-Count Total Testosterone kit (Diagnostic Products). The use of this assay to measure plasma $\mathrm{T}$ has been validated for birds (Tramontin et al., 2001). The minimum detectable plasma $\mathrm{T}$ concentration was $0.2 \mathrm{ng} / \mathrm{ml}$. Samples with undetectable $\mathrm{T}$ levels were treated as having concentrations at this detection limit for statistical analysis.

Histology and brain morphometry. Birds were deeply anesthetized with methoxyflurane and perfused through the heart with heparinized saline followed by $10 \%$ neutral-buffered formalin (NBF). Brains were postfixed in NBF for at least 2 weeks, embedded in gelatin, cryoprotected in a $20 \%$ sucrose and NBF solution, and sectioned in the coronal plane at $50 \mu \mathrm{m}$ on a freezing microtome. Every other section was mounted and stained with thionin. The Nissl-defined borders of song nuclei coincide with the borders as defined by other labels (for review, see Tramontin and Brenowitz, 2000).

We projected a magnified image $(46 \times)$ of each mounted section that contained a song nucleus profile (100 $\mu \mathrm{m}$ sampling interval). We traced onto paper the Nissl-defined borders of unlesioned and remaining lesioned (if any) $\mathrm{HVc}$, as well as RA, area X, $1 \mathrm{MAN}$, and $\mathrm{nXIIts} \mathrm{ipsilateral}$ and contralateral to the HVc lesion. We used the criteria of DeVoogd et al. (1991) to distinguish the tracheosyringeal from the lingual portion of the hypoglossal nucleus (see Smith et al., 1997c). These tracings were scanned into a computer, and the cross-sectional area of each song nucleus profile was calculated using NIH Image software (version 1.57; 
Table 1. Plasma T levels (ng/ml) in the three treatment groups before receiving the SILASTIC implant and at different times after the implant

\begin{tabular}{llrrr} 
Group & Preimplant & Week 2 & Week 4 & Week 6 \\
\hline SD $(n=8)$ & $0.36 \pm 0.21^{a}$ & $0.22 \pm 0.19^{a}$ & $0.07 \pm 0.02^{\mathrm{a}}$ & - \\
Growth $(n=9)$ & $0.14 \pm 0.05^{a}$ & $9.76 \pm 0.66^{b}$ & $10.71 \pm 1.58^{b}$ & - \\
Maintenance $(n=7)$ & $0.11 \pm 0.04^{a}$ & $16.69 \pm 3.23^{c}$ & $8.58 \pm 1.28^{b}$ & $11.70 \pm 0.77^{b, c}$
\end{tabular}

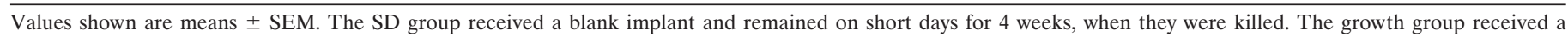

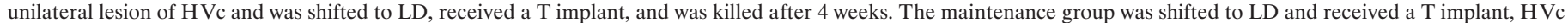
was lesioned at 4 weeks, and the $\mathrm{T}$ implant was replaced then. These birds were killed at 7 weeks.

$a, b, c$ Values with different superscripts differ significantly from each other (SNK post hoc comparison, $p<0.05$, two-tailed).

Wayne Rasband, National Institutes of Health, Bethesda, MD). We estimated the volume of each nucleus using the formula for a cone frustum over each measured profile area (Smith et al., 1995). All brain measurements were made blind to treatment group.

Individual birds may differ in overall brain size and/or histological preparation. To control for such variation, statistical analyses of $\mathrm{HVc}$, $\mathrm{RA}$, area $\mathrm{X}$, and $\mathrm{IMAN}$ were conducted on the volumes of each nucleus divided by the volume of the unlesioned telencephalon; a previous study of GWCS reported no size difference between the right and left telencephalon (Tramontin et al., 2000). nXIIts is located in the brainstem and therefore was only expressed in absolute terms. We estimated the volume of the unlesioned telencephalon by projecting onto paper a magnified image $(14 \times)$ of every sixth mounted section through the telencephalon (600 $\mu \mathrm{m}$ sampling interval). We traced the borders of the telencephalic hemisphere and scanned the tracings into a microcomputer. We defined the borders of the telencephalon as in DeVoogd et al. (1993) and Brenowitz et al. (1998). In sections in which the telencephalon was contiguous with the diencephalon, we used the septomesencephalic tract, anterior commissure, and occipitomesencephalic tract as natural borders. Telencephalon volume was estimated with the formula for a cone frustum.

We also measured neuronal attributes of RA, including neuronal somal area, neuron density, and neuron number, as described below. In wild birds with intact $\mathrm{HVc}$, neuronal size in RA increases and neuronal density decreases when RA grows during the breeding season (Smith et al., 1997c; Tramontin and Brenowitz, 1999, 2000). We wished to determine whether $\mathrm{HVc}$ lesions disrupted these cellular changes in RA. In intact birds the number of neurons in RA does not change when this nucleus grows in the breeding season (Brenowitz et al., 1991; Smith et al., 1995, 1997a,c; Tramontin et al., 1998, 1999; Tramontin and Brenowitz, 2000). It is possible, however, that lesions of $\mathrm{HVc}$ might lead to the loss of neurons in RA when they are derived of trophic support. We measured neuron number in our birds to test this possibility. Cellular attributes of area $\mathrm{X}$ have not been measured in wild birds in different seasons, and we therefore did not measure neuronal traits in this nucleus.

We used a random systematic sampling scheme to measure soma size and neuron density in RA. This procedure was described in detail by Tramontin et al. (1998), who showed that with $50 \mu \mathrm{m}$ Nissl-stained sections, this scheme yielded estimates of neuron density and number that did not differ from those obtained using a stereological optical dissector procedure. Briefly, we captured a video image of RA at 195X magnification using NIH Image. We outlined the borders of RA onscreen and overlaid it with a square grid $42 \mu \mathrm{m}$ per side. Using a random-number generator, we selected one of the first six columns and every sixth column thereafter. For each selected column we randomly selected one square. We counted and measured the somal area of all neurons in that square from a second digitized image of that field captured at $1950 \times$ magnification. In this way we measured at least 100 neurons throughout the RA of each bird, which required sampling 17-23 fields per individual. This sample size is sufficient to encompass all of the variance present in somal area and neuron density in RA (Tramontin et al., 1998).

Statistical analyses. We used separate two-way repeated measures ANOVAs (RMANOVAs) to compare plasma T levels during the first 4 weeks of the study between the SD and growth groups and between the SD and maintenance groups. Sampling time was the repeated measure, and photoperiod or hormone treatment was the unrepeated second factor. A one-way RMANOVA was used to compare plasma T levels across the 7 weeks in the maintenance group. Data for plasma T levels were log-transformed to meet the criteria of normality and equal variance.

We used separate two-way RMANOVAs to compare nuclear and neuronal measurements between the SD and growth groups and between the SD and maintenance groups. The side of the brain analyzed (ipsilateral vs contralateral to the lesion) was the repeated measure, and the photoperiod or hormone treatment was the unrepeated second factor. The growth and maintenance groups did not differ significantly in any measurements (see Tables 2, 3), and we therefore did not perform a single two-way RMANOVA for all three groups. Because we wanted to compare specific attributes between each $\mathrm{LD}+\mathrm{T}$ group and the SD group, we did not pool data from the growth and maintenance groups. The RMANOVAs were followed by one-tailed post hoc pairwise comparisons using the Student-Newman-Keuls (SNK) test. We used onetailed tests because we tested the directional hypotheses that lesions of $\mathrm{HVc}$ would cause regression or prevent growth of ipsilateral nuclear and neuronal attributes. There is no basis for predicting that lesions of $\mathrm{HVc}$ would result in song nuclei or neurons that are larger or more widely spaced than those contralateral to the lesion.

To test the hypothesis that lesions of HVc completely prevented growth or maintenance of the ipsilateral efferent nuclei in the two $\mathrm{LD}+\mathrm{T}$ groups, we used two-tailed $t$ tests to compare measurements contralateral to the lesion in the SD group with measurements ipsilateral to the lesion in the growth and maintenance groups. Two-tailed tests were used for this comparison because there was no a priori basis for predicting whether attributes ipsilateral to the lesion would be greater or less than those contralateral to the lesion in the SD group.

In some birds the lesions spared part of the HVc. To determine the proportion of $\mathrm{HVc}$ damaged by the lesion, we compared the volume of the remaining lesioned $\mathrm{HVc}$ (if any) with that of the contralateral unlesioned HVc. Previous studies have not reported a size difference between the left and right HVc in intact GWCS (Smith et al., 1995, 1997a,b; Tramontin et al., 1998, 1999, 2000; Tramontin and Brenowitz, 2000). We calculated Pearson product moment correlations to determine whether the size of ipsilateral RA and area X or neuronal attributes of RA were related to the size of the remaining $\mathrm{HVc}$ in all three treatment groups. For this and all other tests, the $\alpha$ level was 0.05 .

\section{RESULTS}

\section{Plasma T levels}

Before receiving SILASTIC implants, birds in all three treatment groups had basal plasma T levels typical of nonbreeding whitecrowned sparrows (Table 1). $\mathrm{T}$ implants significantly increased circulating $\mathrm{T}$ concentrations in the growth and maintenance groups above those in the SD group for all postimplant samples (Table $1 ; F \geq 51.78 ; p<0.001$ for photoperiod or hormone treatment factor; $F \geq 20.44 ; p<0.001$ for sampling-time factor during the first 4 weeks, two-way RMANOVA). Plasma T levels were within or above the physiological range for breeding birds (4-10 $\mathrm{ng} / \mathrm{ml})$ at all postimplant sampling times in both LD+T groups. In the maintenance group, plasma $\mathrm{T}$ levels varied significantly across the 7 weeks (Table $1 ; F=4.00 ; p=0.019$, one-way RMANOVA). This pattern reflects a decrease in circulating $\mathrm{T}$ over the 4 weeks after the first implant and then an increase after replacement of the $\mathrm{T}$ pellet at 4 weeks.

\section{Song nuclei: HVc}

Exposure to the long-day photoperiod and $\mathrm{T}$ induced growth of the unlesioned HVc (Table 2). HVc was significantly larger in both the growth $\left[F_{(1,15)}=10.39 ; p=0.006\right.$; SNK $q=4.138 ; p=$ 


\begin{tabular}{|c|c|c|c|}
\hline Region & Treatment group & Ipsilateral & Contralateral \\
\hline \multirow[t]{3}{*}{$\mathrm{HVc}$} & SD & $0.071 \pm 0.019$ & $0.391 \pm 0.045$ \\
\hline & Growth & $0.161 \pm 0.065$ & $0.576 \pm 0.028$ \\
\hline & Maintenance & $0.118 \pm 0.050$ & $0.637 \pm 0.343$ \\
\hline \multirow[t]{3}{*}{ RA } & $\mathrm{SD}$ & $0.128 \pm 0.019$ & $0.170 \pm 0.051$ \\
\hline & Growth & $0.150 \pm 0.035$ & $0.229 \pm 0.046$ \\
\hline & Maintenance & $0.164 \pm 0.114$ & $0.216 \pm 0.008$ \\
\hline \multirow[t]{3}{*}{ Area X } & $\mathrm{SD}$ & $0.879 \pm 0.177$ & $1.106 \pm 0.304$ \\
\hline & Growth & $1.405 \pm 0.107$ & $1.611 \pm 0.289$ \\
\hline & Maintenance & $1.181 \pm 0.062$ & $1.313 \pm 0.116$ \\
\hline \multirow[t]{3}{*}{$1 \mathrm{MAN}$} & $\mathrm{SD}$ & $0.054 \pm .00671$ & $0.059 \pm .009$ \\
\hline & Growth & $0.075 \pm 0080$ & $0.071 \pm .0066$ \\
\hline & Maintenance & $0.067 \pm .0074$ & $0.066 \pm .0061$ \\
\hline \multirow[t]{3}{*}{ nXIIts } & $\mathrm{SD}$ & $0.033 \pm .0009$ & $0.034 \pm .0119$ \\
\hline & Growth & $0.044 \pm .0002$ & $0.046 \pm .0053$ \\
\hline & Maintenance & $0.039 \pm .0048$ & $0.039 \pm .0046$ \\
\hline \multirow[t]{3}{*}{ Telencephalon } & $\mathrm{SD}$ & & $275.15 \pm 10.21$ \\
\hline & Growth & & $284.13 \pm 5.50$ \\
\hline & Maintenance & & $257.49 \pm 9.10$ \\
\hline
\end{tabular}

Values shown are means \pm SEM. For telencephalon, only the unlesioned contralateral hemisphere was measured. See text for sample sizes.

$0.007]$ and maintenance $\left[F_{(1,13)}=7.92 ; p=0.015 ; \mathrm{SNK} q=4.060\right.$; $p=0.009]$ groups than in the SD group. There was no significant difference in the size of unlesioned $\mathrm{HVc}$ between the two LD+T groups $\left[F_{(1,14)}=0.567 ; p=0.464 ; \mathrm{SNK} q=1.628 ; p=0.260\right]$.

There was individual variation in the amount of HVc eliminated by the lesion. In the SD group, the lesion eliminated $43-100 \%$ of $\mathrm{HVc}$, as measured in comparison with the unlesioned contralateral HVc. In the growth group, 28-100\% of $\mathrm{HVc}$ was damaged by the lesion. In the maintenance group, $36-100 \%$ of $\mathrm{HVc}$ was lesioned. The three treatment groups did not differ significantly in the percent of $\mathrm{HVc}$ lesioned $\left[F_{(2,23)}=0.177 ; p=\right.$ 0.839, one-way ANOVA].

\section{RA}

\section{SD group: volume}

Afferent input from $\mathrm{HVc}$ was required to maintain RA even at its regressed size in SD birds. RA was significantly smaller ipsilateral to the HVc lesion than contralateral (see Fig. 3; Tables 2, 3). The size of RA was not correlated with the size of the remaining $\mathrm{HVc}$ $(r=-0.331 ; p=0.423)$.

\section{SD group: neuronal attributes}

In the SD birds, the HVc lesions altered neuron density and number in RA. Neuron density was greater and neuron number was lower ipsilateral to the lesion than contralateral (see Fig. 5; see Table 5). None of these neuronal traits in ipsilateral RA was significantly correlated with the size of $\mathrm{HVc}$ remaining after the lesion (Pearson $r \leq-0.529 ; p \geq 0.177 ; n=8$ ).

\section{Growth group: volume}

Lesions of HVc blocked the LD+T-induced growth of RA in the growth group. Contralateral to the lesion, the volume of RA increased significantly compared with that of the SD birds (see Fig. 3; Tables 2-4). RA was smaller ipsilateral to the lesion than contralateral within the growth birds (Figs. 2, 3; Tables 2, 3). The volume of RA ipsilateral to the lesion was highly correlated with the volume of the remaining $\mathrm{HVc}\left(r=0.940 ; p=1.6 \times 10^{-4}\right.$; Fig.
4). The volume of RA ipsilateral to the lesion in the growth group did not differ from the ipsilateral or contralateral volumes in the SD birds (Fig. 3; Tables 2, 3).

\section{Growth group: neuronal attributes}

Neuronal attributes in RA were affected by the HVc lesions within the growth birds. In the ipsilateral RA, somal area was significantly smaller than that contralateral to the lesion (Fig. 5; Tables 3, 5). Neuron density was greater in ipsilateral RA, and this difference approached significance ( $p=0.0645$; Fig. 5; Tables 3, 5). Mean neuron number in RA was greater contralateral to the lesion in the growth group (Fig. 5); the side-of-brain factor in the RMANOVA approached significance ( $p=0.063$; Table 3$)$, and the post hoc SNK test indicated a significant difference between the ipsilateral and contralateral sides of RA (Table 5). The number of neurons in ipsilateral RA was correlated with the size of HVc remaining after the lesion (Pearson $r=0.743 ; p=$ $0.022 ; n=9)$. Ipsilateral to the lesion, the somal area of RA neurons was significantly greater in the growth group than in the SD group (Fig. 5; Tables 3, 5). None of these neuronal traits differed between the ipsilateral RA in growth birds and the contralateral RA in the SD group (Fig. 5; Tables 3, 5).

\section{Maintenance group: volume}

Afferent input from $\mathrm{HVc}$ was necessary to maintain RA at its enlarged size in the maintenance group. Contralateral to the lesion, the volume of RA in this group was larger than that in the SD birds (Fig. 3; Tables 2-4). RA in the maintenance birds was smaller ipsilateral to the lesion than contralateral (Fig. 3; Tables $2-4)$. The volume of RA ipsilateral to the lesion was correlated with the volume of the remaining HVc $(r=0.835 ; p=0.02$; Fig. 4 ). The volume of RA ipsilateral to the lesion in the maintenance group was significantly larger than the ipsilateral volume in the SD birds but did not differ from the contralateral volume in the SD birds (Fig. 3; Tables 2-4).

\section{Maintenance group: neuronal attributes}

Neuron size in RA within the maintenance group was marginally decreased by the HVc lesions (Fig. 5; Tables 3, 5). In this group the lesions increased neuronal density, which was significantly greater in ipsilateral RA (Fig. 5; Tables 3, 5). Within the maintenance group, there was no effect of the lesions on neuron number in RA (Fig. 5; Tables 3, 5). None of these neuronal traits in ipsilateral RA was correlated with the amount of $\mathrm{HVc}$ remaining after the lesion (Pearson $r \leq 0.522 ; p \geq 0.229 ; n=7$ ). Ipsilateral to the lesion, neither somal area nor neuron density differed between the SD and maintenance groups (Fig. 5; Tables $3,5)$. Neuron number was slightly greater in ipsilateral RA in the maintenance than in the SD birds, although this difference did not reach significance ( $p=0.068$; Fig. 5; Tables 3, 5).

\section{Growth versus maintenance groups}

The RMANOVA indicated that there was not a significant difference in the volume of RA between the growth and maintenance groups (Table 3). The post hoc SNK tests showed, however, that there were some differences in the effects of the HVc lesions on neuronal attributes of RA in these two groups (Table 5). The lesions significantly reduced neuron number in ipsilateral RA in the growth birds but not in the maintenance group. The lesions led to a highly significant increase in neuron density in ipsilateral RA in the maintenance group but a smaller increase that approached but did not reach significance in the growth group $(p=$ 
Table 3. Statistics for two-way RMANOVAs of volumes of song nuclei and neuronal attributes of RA in SD, growth, and maintenance groups, ipsilateral and contralateral to unilateral lesion of HVc

\begin{tabular}{|c|c|c|c|c|c|c|}
\hline \multirow[b]{2}{*}{ Attribute } & \multicolumn{2}{|l|}{$\mathrm{SD} \times$ growth } & \multicolumn{2}{|l|}{$\mathrm{SD} \times$ maintenance } & \multicolumn{2}{|l|}{ Growth $\times$ maintenance } \\
\hline & Factor 1 & Factor 2 & Factor 1 & Factor 2 & Factor 1 & Factor 2 \\
\hline RA volume & $6.61_{1,15}(0.021)$ & $51.01_{1,15}(<0.001)$ & $18.58_{1,13}(<0.001)$ & $42.08_{1,13}(<0.001)$ & $2.31_{1,14}(0.151)$ & $80.79_{1,14}(<0.001)$ \\
\hline Area $\mathrm{X}$ volume & $14.23_{1,13}(0.002)$ & $12.43_{1,13}(0.004)$ & $12.42_{1,13}(0.004)$ & $9.14_{1,13}(0.010)$ & $0.21_{1,14}(0.656)$ & $15.51_{1,14}(0.001)$ \\
\hline nXIIts volume & $8.27_{1,15}(0.012)$ & $0.52_{1,15}(0.483)$ & $0.28_{1,11}(0.607)$ & $0.10_{1,11}(0.756)$ & $8.49 \times 10^{-15}{ }_{1,11}(1.0)$ & $5.48 \times 10^{-4}{ }_{1,11}(1.0)$ \\
\hline $1 \mathrm{MAN}$ volume & $2.66_{1,14}(0.125)$ & $0.01_{1,14}(0.940)$ & $3.78_{1,12}(0.076)$ & $0.25_{1,12}(0.625)$ & $2.49 \times 10^{-3}{ }_{1,14}(0.961)$ & $0.897_{1,14}(0.669)$ \\
\hline RA somal area & $10.15_{1,15}(0.006)$ & $6.20_{1,15}(0.025)$ & $1.80_{1,13}(0.203)$ & $5.27_{1,13}(0.039)$ & $1.63_{1,14}(0.223)$ & $8.32_{1,14}(0.012)$ \\
\hline RA neuron density & $4.32_{1,15}(0.055)$ & $4.02_{1,15}(0.063)$ & $4.65_{1,13}(0.050)$ & $19.54_{1,13}(<0.001)$ & $0.11_{1,14}(0.742)$ & $6.88_{1,14}(0.020)$ \\
\hline RA neuron number & $0.94_{1,15}(0.349)$ & $4.01_{1,15}(0.063)$ & $1.06_{1,13}(0.323)$ & $3.15_{1,13}(0.099)$ & $5.71 \times 10^{-3}{ }_{1,14}(0.941)$ & $1.82_{1,14}(0.199)$ \\
\hline
\end{tabular}

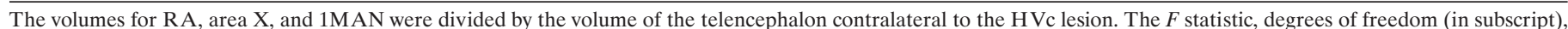

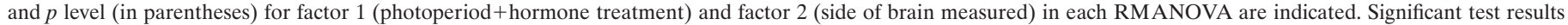
are shown in bold type. See text for explanation of group comparisons.

Table 4. Statistics for pairwise comparisons of volumes of song nuclei in SD, growth, and maintenance groups, ipsilateral and contralateral to unilateral lesion of HVc

\begin{tabular}{|c|c|c|c|}
\hline Groups compared & RA & Area $\mathrm{X}$ & nXIIts \\
\hline SD contra versus SD ipsi & $5.08(<0.0015)$ & $3.89(0.0085)$ & $0.20(0.390)$ \\
\hline Growth contra versus growth ipsi & $9.34(<0.0005)$ & $4.81(0.002)$ & $<10^{-5}(1.00)$ \\
\hline Maintenance contra versus maintenance ipsi & $7.34(<0.0005)$ & $3.07(0.024)$ & $<10^{-5}(1.00)$ \\
\hline SD contra versus growth contra & $4.50(0.0045)$ & $4.61(0.002)$ & $3.98(0.006)$ \\
\hline SD ipsi versus growth ipsi & $1.64(0.242)$ & $4.91(0.0015)$ & $3.64(0.0095)$ \\
\hline SD contra versus maintenance contra & $5.92(<0.0005)$ & $3.68(0.008)$ & $0.90(0.269)$ \\
\hline SD ipsi versus maintenance ipsi & $4.64(0.002)$ & $4.80(0.0015)$ & $0.91(0.265)$ \\
\hline Growth contra versus maintenance contra & $1.23(0.20)$ & $0.82(0.286)$ & $<10^{-5}(1.00)$ \\
\hline Growth ipsi versus maintenance ipsi & $2.67(0.074)$ & $0.452(0.377)$ & $<10^{-5}(1.00)$ \\
\hline SD contra versus growth ipsi & $1.56(0.07)$ & $-1.56(0.072)$ & $-2.22(0.043)$ \\
\hline SD contra versus maintenance ipsi & $-0.42(0.342)$ & $-0.75(0.234)$ & $-0.75(0.467)$ \\
\hline
\end{tabular}

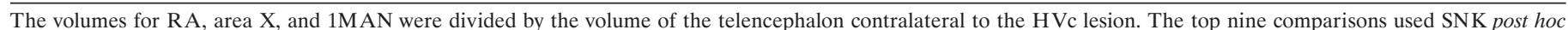

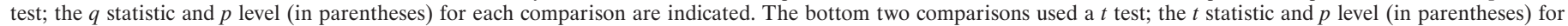
each comparison are presented. Significant test results are shown in bold type. See text for sample sizes. contra, Contralateral; ipsi, ipsilateral.

0.0645). Somal area was significantly reduced in ipsilateral RA of both the growth and maintenance groups.

\section{Area $\mathrm{X}$}

SD group

This nucleus required afferent input from $\mathrm{HVc}$ to remain at its regressed size in SD birds. This nucleus was smaller ipsilateral to the lesion than contralateral (Fig. 3; Tables 2-4). The volume of ipsilateral area $\mathrm{X}$ was not correlated with the volume of $\mathrm{HVc}$ $(r=-0.281 ; p=0.50)$.

\section{Growth group}

The full LD+T-induced growth of area $\mathrm{X}$ in the growth group was blocked by the lesion of HVc. The volume of area X contralateral to the lesion in the growth birds was significantly greater than that in the SD birds (Fig. 3; Tables 2-4). Within the growth group, area $\mathrm{X}$ was smaller ipsilateral to the lesion than contralateral (Figs. 2, 4; Tables 2-4). The volume of area X ipsilateral to the lesion was marginally correlated with the volume of the remaining $\mathrm{HVc}(r=0.738, p=0.058$; Fig. 4). Area $\mathrm{X}$ differed from RA in that the volume ipsilateral to the lesion in the growth group was greater than the ipsilateral volume in the SD birds (Fig. 3; Tables 2-4). The mean volume of area X ipsilateral to the lesion in the growth group was not significantly different from the volume contralateral to the lesion in the SD birds (Fig. 3; Tables 2-4).

\section{Maintenance group}

Area $\mathrm{X}$ required afferent input from $\mathrm{HVc}$ to maintain its enlarged size in the maintenance group. The volume of area $\mathrm{X}$ contralateral to the lesion was significantly larger in this group than in the SD birds (Fig. 3; Tables 2-4). Area X within the maintenance group was smaller ipsilateral to the lesion than contralateral (Fig. 3; Tables 2-4). The volume of area X ipsilateral to the lesion was not significantly correlated with the volume of the remaining $\mathrm{HVc}(r=-0.687 ; p=0.088)$. The volume of area $\mathrm{X}$ ipsilateral to the lesion in the maintenance birds was significantly larger than the ipsilateral volume in the SD birds but did not differ from the contralateral volume in the SD birds (Fig. 3; Tables 2-4).

\section{Growth versus maintenance groups}

The effects of HVc lesions on area $\mathrm{X}$ were similar whether they were made before or after growth induced by $\mathrm{LD}+\mathrm{T}$. There were no significant differences in the volume of area $\mathrm{X}$ between the growth and maintenance groups (Fig. 3; Tables 2-4).

\section{IMAN}

$\mathrm{HVc}$ lesions had no effect on the volume of IMAN in any of the treatment groups. There were no significant differences between the ipsilateral and contralateral volumes of IMAN in the three groups (Tables 2, 3). 1MAN did not grow significantly in response 


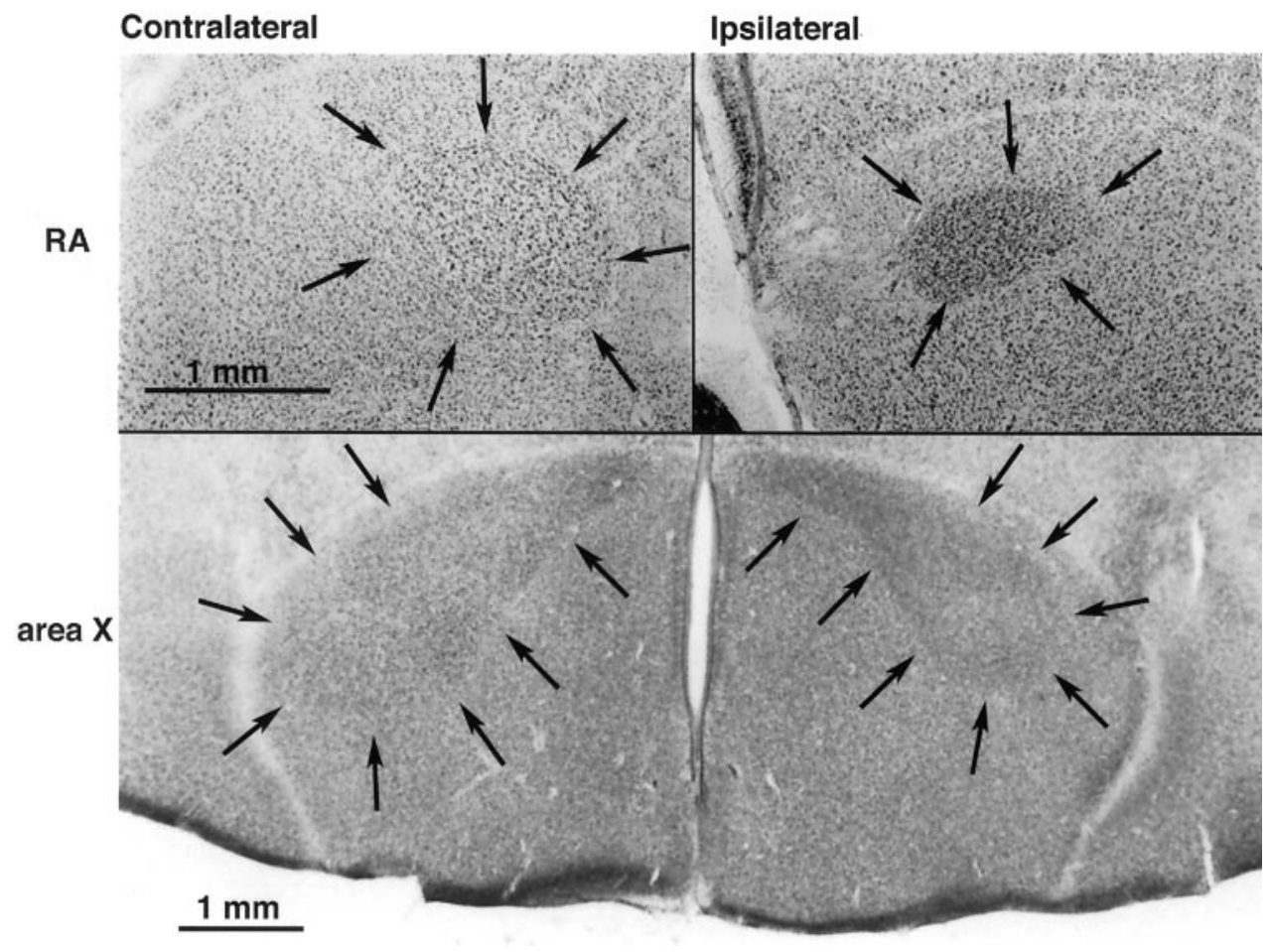

Figure 2. Photographs showing RA (top) and area $\mathrm{X}$ (bottom) ipsilateral (right) and contralateral (left) to a unilateral lesion of $\mathrm{HVc}$ in a male white-crowned sparrow exposed to long days plus testosterone treatment for $30 \mathrm{~d}$ after the lesion. The maximum extent of each nucleus is indicated with arrows. Scale bars, $1 \mathrm{~mm}$. to the LD+T treatment (Tables 2, 3). In the RMANOVAs the photoperiod plus hormone treatment factor was not significant for any of the groups (Table 3).

The volume of IMAN was correlated with the size of other nuclei in some of the treatment groups. Ipsilateral to the lesion in the SD birds, IMAN was correlated with area $\mathrm{X}(r=0.752 ; p=$ $0.032)$. In the growth group, the volume of ipsilateral IMAN was related to the volume of RA $(r=0.710 ; p=0.032)$.

\section{nXIIts}

The HVc lesions did not affect the size of nXIIts in any treatment group. There was no difference between the ipsilateral and contralateral volumes of nXIIts in any treatment group (Tables 2-4). nXIIts increased in volume significantly in the growth group (Tables 2-4). In the post hoc tests, both the ipsilateral and contralateral $\mathrm{nXIIts}$ in the growth group were larger than their counterparts in the SD birds (Tables 2,4). Ipsilateral nXIIts in the growth group was also larger than the contralateral nXIIts in the SD group (Tables 2,4). The mean volume of nXIIts on both sides of the brain in the maintenance group was intermediate between those of the other two treatment groups and did not differ significantly from either group (Tables 2-4).

The volume of ipsilateral nXIIts in the maintenance group was correlated with the size of RA $(r=0.889 ; p=0.044)$.

\section{DISCUSSION}

Afferent input is known to be important for the perinatal development and maintenance of neurons (for review, see Oppenheim, 1991). Furthermore, trans-synaptic effects of gonadal steroids are known to influence the development of neural circuits (for review, see Beyer and Feder, 1987). Our study demonstrates that afferent input is also necessary for the growth of adult brain nuclei in response to seasonal hormonal and photoperiod cues; seasonal growth is a common feature of adult vertebrate brains (for review, see Tramontin and Brenowitz, 2000).

Previous research demonstrated that seasonal growth of the song circuits is primarily regulated by changes in plasma $\mathrm{T}$ levels (Gulledge and Deviche, 1997; Smith et al., 1997a; Ball, 2000). We found that lesions of $\mathrm{HVc}$ blocked or decreased the LD+Tinduced growth of its efferent targets RA and area $\mathrm{X}$ in the growth group. Our study suggests that $\mathrm{T}$ acts directly on $\mathrm{HVc}$, which in turn stimulates the growth of RA and area $\mathrm{X}$ via trans-synaptic effects. AR are present in both RA-projecting and area X-projecting neurons in HVc (Sohrabji et al., 1989). Additional support for our suggestion comes from the observation that small unilateral implants of $\mathrm{T}$ adjacent to $\mathrm{HVc}$ induced growth of ipsilateral but not contralateral HVc, RA, and area X in GWCS, whereas $\mathrm{T}$ implants near RA did not induce growth of these nuclei (Brenowitz and Lent, 2000).

Afferent input from $\mathrm{HVc}$ was also necessary to maintain RA and area $\mathrm{X}$ after they had grown in response to LD+T treatment. $\mathrm{RA}$ and area $\mathrm{X}$ contralateral to the lesion in the maintenance group were larger than these nuclei in the SD group and did not differ in size from the contralateral nuclei in the growth birds. These observations show that RA and area X grew on both sides of the brain before the $\mathrm{HVc}$ lesion in the maintenance birds. The smaller volume of the efferent nuclei ipsilateral to the lesion in this group can therefore be interpreted as indicating a reduction in size as a result of the lesion, rather than a failure to initially grow in response to $\mathrm{LD}+\mathrm{T}$.

The volume of the ipsilateral RA was strongly correlated with the size of the remaining $\mathrm{HVc}$, if any, in both the growth and maintenance groups. These correlations indicate that the extent to which $\mathrm{LD}+\mathrm{T}$ induced or maintained growth of RA was directly related to the amount of trophic support that $\mathrm{HVc}$ continued to provide after the lesion.

The size of area $\mathrm{X}$, in contrast to RA, was only marginally correlated with the amount of $\mathrm{HVc}$ that remained after the lesion in the growth group and was not correlated in the maintenance group. Furthermore, ipsilateral area X was significantly larger in these groups than in the SD birds. Two factors might have 

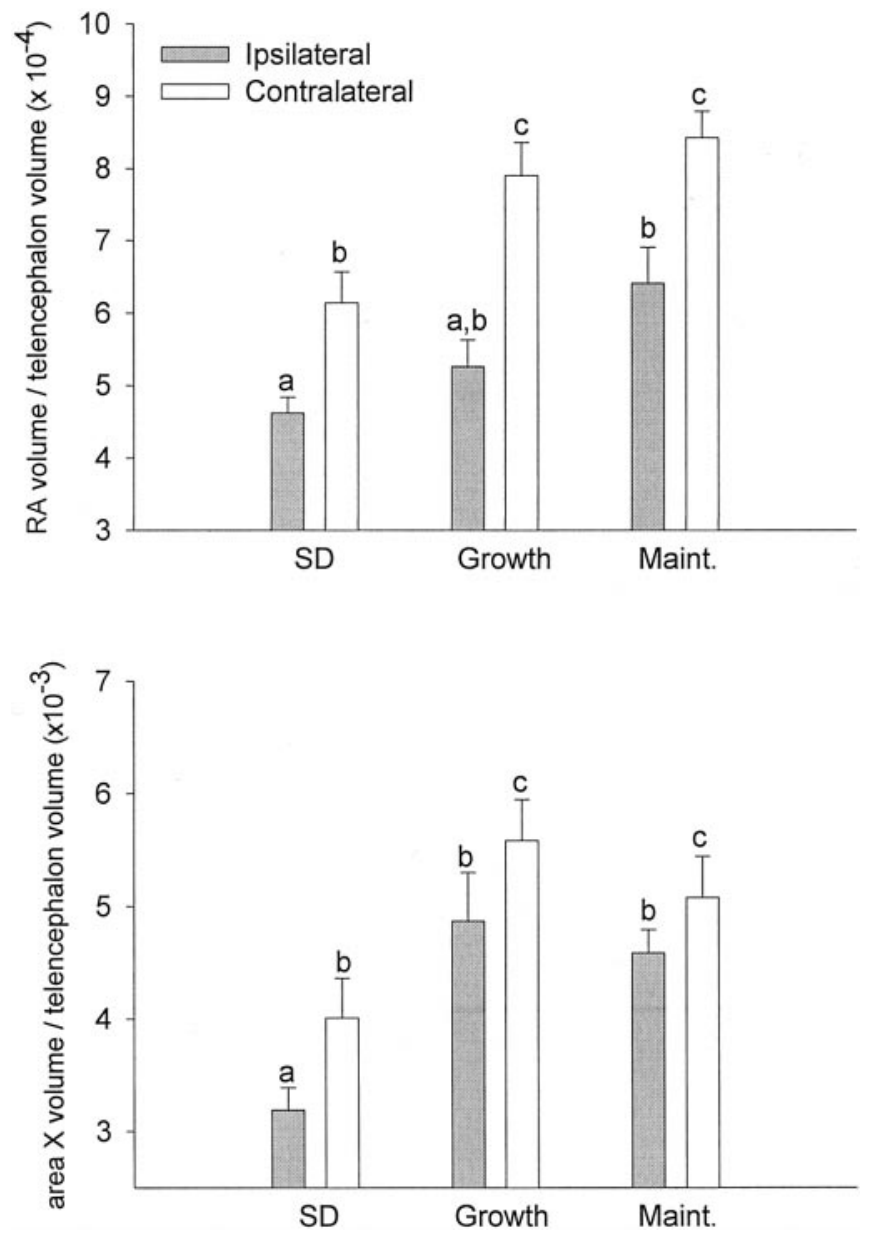

Figure 3. The volumes (mean \pm SEM) of RA (top) and area X (bottom) ipsilateral and contralateral to the lesioned $\mathrm{HVc}$ in the SD, growth, and maintenance (maint.) treatment groups. The volume of each nucleus was divided by the volume of the entire telencephalon contralateral to the lesioned HVc. Different letters above the vertical bars indicate significant differences in volume between sides of the brain and between treatment groups.

contributed to this pattern. First, there are area X-projecting (but not RA-projecting) neurons in para-HVc, a region immediately caudal to HVc (Nordeen et al., 1987; Johnson and Bottjer, 1995). Some of these neurons were likely spared by our HVc lesions and may have provided adequate trophic support to prevent area $\mathrm{X}$ from regressing to the size found in the SD birds, regardless of how much HVc remained. These area X-projecting neurons contain receptors for estradiol, which is available by aromatization of T (Nordeen et al., 1987; Johnson and Bottjer, 1995; Schlinger, 1997). Second, there is evidence that area X in GWCS grows to a small extent in response to effects of photoperiod independent of gonadal steroids. In a previous study, area $\mathrm{X}$ in castrated GWCS exposed to LD was intermediate in size between castrates exposed to SD and castrates exposed to SD+T (Smith et al., 1997a). A similar effect may have played a role in preventing area $\mathrm{X}$ in the $\mathrm{LD}+\mathrm{T}$ birds from regressing fully down to the size observed in the SD birds.

Neurons in RA of intact birds have high levels of AR (Smith et al., 1996). In the absence of afferent input from $\mathrm{HVc}$, however, high plasma $\mathrm{T}$ concentrations were not sufficient to induce or maintain growth of RA. Potentially, the loss of afferent input from $\mathrm{HVc}$ downregulated $\mathrm{AR}$ expression in RA neurons. A
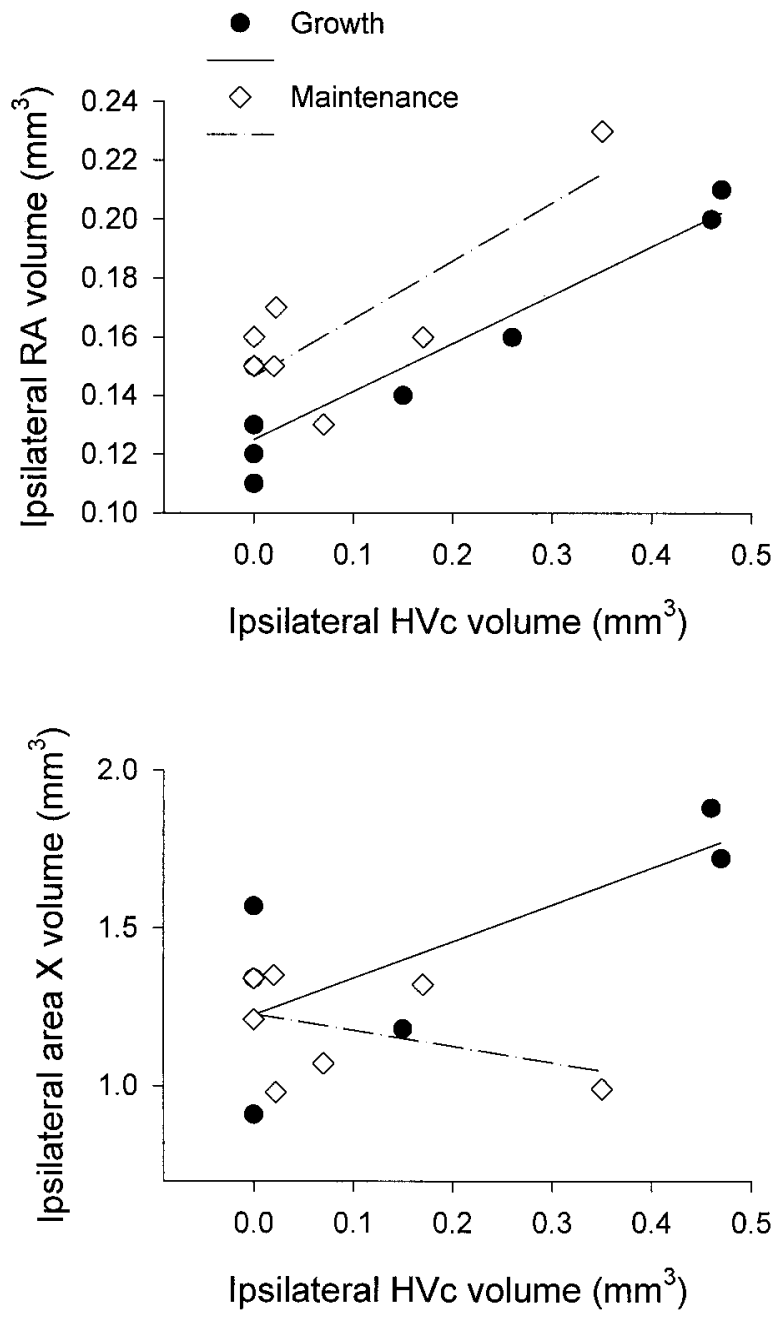

Figure 4. The relationship between the volume of $\mathrm{HVc}$ remaining after the lesion, if any, and the volumes of RA (top) and area X (bottom) ipsilateral to the lesion in the growth and maintenance groups.

decrease in AR levels would have made RA less sensitive to the stimulatory effects of T. Alternatively, the growth and maintenance of RA may require an interaction between trans-synaptic influences from HVc and the direct action of T on RA.

Systemic T treatment clearly influences area X (present report) (Konishi and Akutagawa, 1981; Smith et al., 1997a), but it is unlikely that $\mathrm{T}$ acts directly on this nucleus. Steroid accumulation, immunocytochemical, and in situ hybridization studies show that area X neurons have few or no AR (Arnold et al., 1976; Balthazart et al., 1992; Smith et al., 1996; Bernard et al., 1999; Metzdorf et al., 1999).

The SD group demonstrated that afferent input from $\mathrm{HVc}$ is also required for $\mathrm{RA}$ and area $\mathrm{X}$ to maintain their normal regressed, nonbreeding season size. Apparently, HVc continues to provide trophic support at a basal level that keeps the efferent nuclei somewhat larger than they would be in the absence of this support. It seems unlikely that support of the song nuclei in SD birds is based on gonadal androgens because the testes are regressed and plasma $\mathrm{T}$ levels are unmeasurably low in GWCS outside the breeding season (Wingfield and Farner, 1978). It may be that there is a constitutive level of electrical activity across the synapses between $\mathrm{HVc}$ axon terminals and their postsynaptic targets. Alternatively, there may be an ongoing release of neuro- 

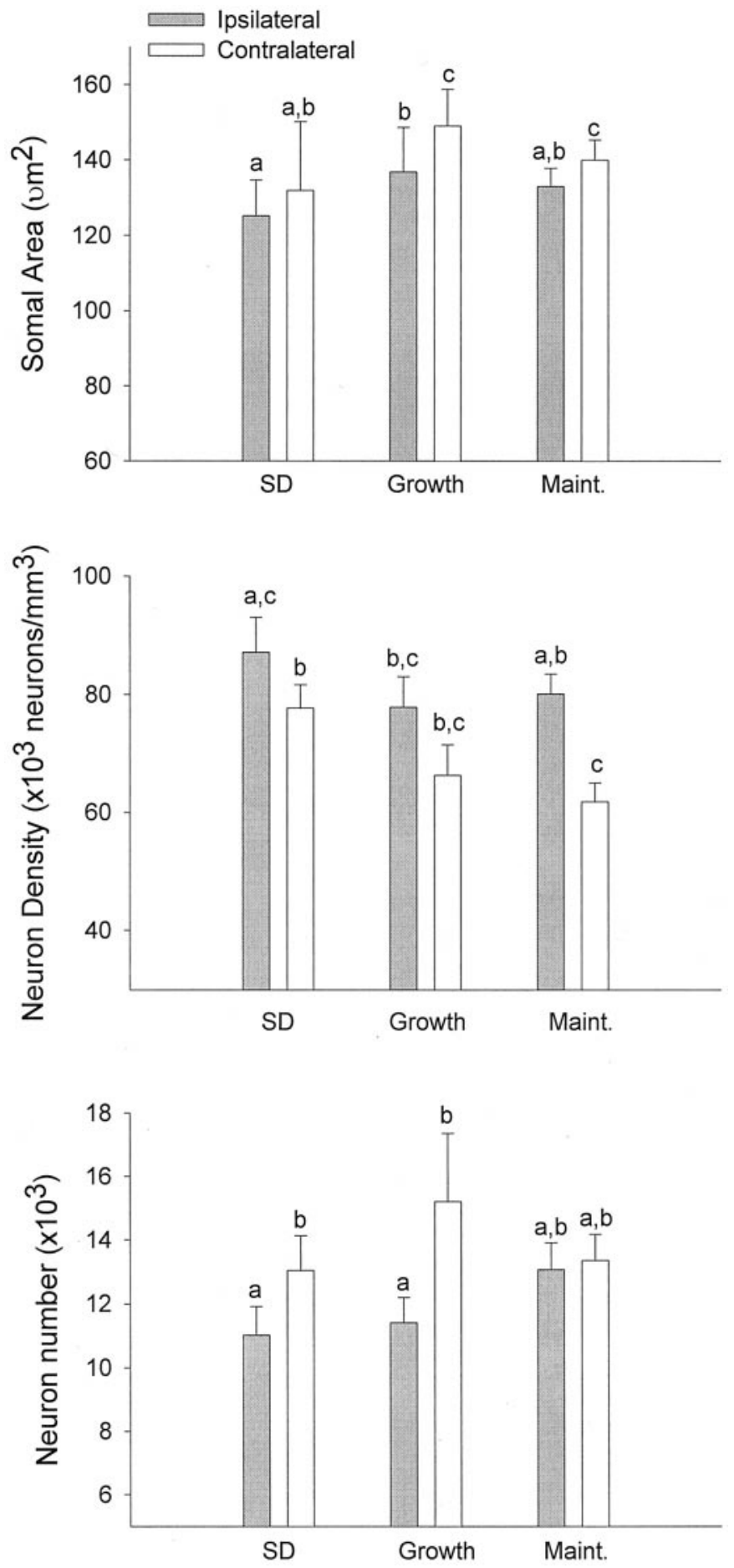

Figure 5. Neuronal attributes (mean \pm SEM) of RA ipsilateral and contralateral to the lesioned $\mathrm{HVc}$ in the SD, growth, and maintenance groups. Different letters above the vertical bars indicate significant differences between sides of the brain and between treatment groups.

trophic factors by $\mathrm{HVc}$ axon terminals that maintain RA and area $\mathrm{X}$ neurons. The potential roles of synaptic activity and neurotrophins in providing trophic support are discussed in more detail below.

The neuronal measurements in RA provide insights into the cellular basis of the HVc lesion effects in the different treatment groups. Previous reports showed that the seasonal growth of RA is primarily caused by increases in soma size, dendritic arborizations, and neuronal spacing and that neuron number in RA does not change seasonally (for review, see Tramontin and Brenowitz, 2000).

The HVc lesions significantly decreased neuron number in both the SD and growth groups but not in the maintenance birds. This comparison suggests that withdrawing afferent input from RA when birds had low plasma $\mathrm{T}$ and RA was regressed led to neuronal loss. The strong correlation $(r=0.74)$ between RA neuron number and the amount of $\mathrm{HVc}$ remaining after the lesion in the growth birds supports this suggestion. High plasma $\mathrm{T}$ and a fully grown RA in the maintenance birds appear to have protected RA neurons from dying after HVc was lesioned. Neuron number in RA of the maintenance group was not correlated with the size of $\mathrm{HVc}$ after the lesion. It is possible that $\mathrm{T}$ acted directly on RA neurons to prevent them from dying in these birds, although high $\mathrm{T}$ was not adequate to maintain the size or spacing of these neurons when afferent input was removed. If this was the case, then neuronal loss must have occurred relatively rapidly in the growth birds because they received a $T$ implant $1 \mathrm{~d}$ after HVc was lesioned.

Neuron density in RA was increased by the HVc lesions in all three groups, although the decrease in the growth group did not reach significance $(p=0.0645)$. Decreased spacing may reflect a decrease in dendritic arborizations (DeVoogd and Nottebohm, 1981; Hill and DeVoogd, 1991). The change in density was most pronounced for the maintenance birds, as shown in the $p$ levels of the post hoc tests. In the SD and growth groups, increased neuron density may have been partially offset by the decreases in neuron number.

Neuron size in RA was decreased by the HVc lesions in the growth and maintenance groups but not in the SD birds. Afferent input from $\mathrm{HVc}$ is necessary both to grow and to maintain large RA neurons in birds exposed to LD+T. There may have been a "floor" effect in the SD birds, in which neurons in the regressed RA were already at a minimum size and not able to regress further after the lesions.

The specific nature of the trophic support provided by $\mathrm{HVc}$ to its efferent targets remains to be determined. Chemical neurotransmission associated with electrical activity across synapses may have neurotrophic effects on postsynaptic neurons (Balazs et al., 1989; Brenneman et al., 1990a,b; Rubel et al., 1990; Oppenheim, 1991; Galli-Resta et al., 1993). The release of neurotransmitter molecules from $\mathrm{HVc}$ axon terminals in the current study may have had trophic effects on neurons in RA and area X. Alternatively, or in addition, presynaptic terminals from $\mathrm{HVc}$ may have released neurotrophins that stimulated growth of postsynaptic neurons. Neurotrophins can be transported anterogradely and taken up by postsynaptic neurons (von Bartheld et al., 1996). Neurotrophins influence the juvenile development of the song circuits (Johnson et al., 1997; Akutagawa and Konishi, 1998; Dittrich et al., 1999). Also, Rasika et al. (1999) showed that T-induced growth of HVc in adult female canaries (Serinus canaria) is mediated by the action of brain-derived neurotrophic factor (BDNF) on $\mathrm{HVc}$ neurons. BDNF mRNA is expressed in $\mathrm{RA}$-projecting and, to a lesser extent, area X-projecting neurons of HVc in singing adult male canaries (Li et al., 2000). The effects of $\mathrm{LD}+\mathrm{T}$ on $\mathrm{HVc}$ and the efferent nuclei in our study may have also been mediated by the action of neurotrophins. It is possible that the specific nature of trophic activity provided by $\mathrm{H} \mathrm{Vc}$ to its efferents (i.e., chemical neurotransmission vs neurotrophins), or 


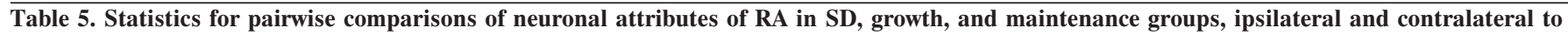
unilateral lesion of HVc

\begin{tabular}{|c|c|c|c|}
\hline Groups compared & Somal area & Neuron density & Neuron number \\
\hline SD contra versus SD ipsi & $1.46(0.158)$ & $3.12(0.023)$ & $3.22(0.02)$ \\
\hline Growth contra versus growth ipsi & $3.92(0.008)$ & $2.27(0.0645)$ & $2.70(0.038)$ \\
\hline Maintenance contra versus maintenance ipsi & $2.53(0.048)$ & $3.03(0.025)$ & $0.42(0.384)$ \\
\hline SD contra versus growth contra & $4.45(0.002)$ & $2.23(0.063)$ & $1.56(0.139)$ \\
\hline SD ipsi versus growth ipsi & $2.79(0.030)$ & $1.82(0.104)$ & $0.28(0.4225)$ \\
\hline SD contra versus maintenance contra & $1.92(0.0955)$ & $3.63(0.009)$ & $0.33(0.408)$ \\
\hline SD ipsi versus maintenance ipsi & $1.58(0.1395)$ & $1.62(0.133)$ & $2.20(0.068)$ \\
\hline Growth contra versus maintenance contra & $2.117(0.074)$ & $0.96(0.2525)$ & $1.32(0.180)$ \\
\hline Growth ipsi versus maintenance ipsi & $0.90(0.266)$ & $0.49(0.367)$ & $1.18(0.206)$ \\
\hline SD contra versus growth ipsi & $-0.92(0.374)$ & $-0.02(0.981)$ & $1.24(0.235)$ \\
\hline SD contra versus maintenance ipsi & $-0.32(0.752)$ & $-0.46(0.653)$ & $-0.02(0.985)$ \\
\hline
\end{tabular}

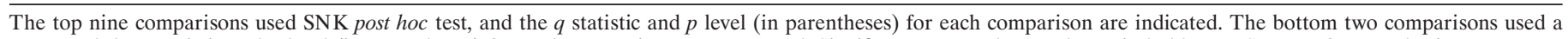
$t$ test, and the $t$ statistic and $p$ level (in parentheses) for each comparison are presented. Significant test results are shown in bold type. See text for sample sizes.

the relative contributions of these factors, differed between the $\mathrm{SD}$ and the $\mathrm{LD}+\mathrm{T}$ conditions.

$\mathrm{RA}$ and area $\mathrm{X}$ each receive afferent input from $1 \mathrm{MAN}$ as well as $\mathrm{HVc}$, but the IMAN input was not sufficient for the maintenance or for full LD+T-induced growth of these regions after HVc lesions. IMAN neurons contain AR, as do HVc neurons, but IMAN does not change in size seasonally in white-crowned sparrows (present report) (Smith et al., 1995, 1997a; Brenowitz et al., 1998; Tramontin and Brenowitz, 2000). Taken together, these observations indicate that the presence of $\mathrm{AR}$ in a given nucleus is not sufficient to induce or maintain growth either of that nucleus or of its efferent targets in response to high plasma $\mathrm{T}$ levels.

The HVc lesions had no effect on the volumes of IMAN or nXIIts, which are both separated from HVc by multiple synapses. These results suggest that the effects of the $\mathrm{HVc}$ lesions were limited to nuclei that receive direct afferent input from $\mathrm{HVc}$ (i.e., $\mathrm{RA}$ and area X).

nXIIts did grow in response to LD+T (see also Smith et al., 1997a). There are several possible explanations for this growth in the absence of HVc input to the motor circuit. (1) Neurons in nXIIts have AR (Arnold et al., 1976) and may have responded directly to the T treatment. (2) T may have directly stimulated the syringeal muscles, which have AR (Lieberburg and Nottebohm, 1979; Luine et al., 1980, 1983; Smith et al., 1996). The motor neurons in nXIIts innervate these muscles and might have derived retrograde trophic support from them, as observed in the spinal nucleus of the bulbocavernosus of rats (Fishman et al., 1990; Fishman and Breedlove, 1992) and the laryngeal motor nucleus of Xenopus (Kelley, 1986). (3) Neurons in nXIIts receive afferent input from the dorsomedial portion of the intercollicular nucleus (ICo), which has AR (Soma et al., 1998). T may have acted on ICo neurons that could then have had trophic effects on postsynaptic nXIIts neurons. (4) RA may have provided adequate trophic support to nXIIts neurons even in the absence of input from $\mathrm{HVc}$.

In conclusion, seasonal change in brain morphology is a common feature of vertebrate brain organization. We have shown that afferent input from the avian song nucleus $\mathrm{HVc}$ is necessary for both the seasonal growth and maintenance of its efferent targets. Exploring the specific mechanisms underlying the trophic support provided by $\mathrm{HVc}$ represents a logical extension of our study. It will be productive to address this issue in a broad array of vertebrate neural circuits that demonstrate adult seasonal plasticity.

\section{REFERENCES}

Akutagawa E, Konishi M (1994) Two separate areas of the brain differentially guide the development of a song control nucleus in the zebra finch. Proc Natl Acad Sci USA 91:12413-12417.

Akutagawa E, Konishi M (1998) Transient expression and transport of brain-derived neurotrophic factor in male zebra finch's song system during vocal development. Proc Natl Acad Sci USA 95:11429-11434.

Arnold AP, Nottebohm F, Pfaff DW (1976) Hormone concentrating cells in vocal control and other areas of the brain of the zebra finch (Poephila guttata). J Comp Neurol 165:487-511.

Balazs R, Hack N, Jorgensen OS, Cotman CW (1989) N-methyl-Daspartate promotes the survival of cerebellar granule cells: pharmacological characterization. Neurosci Lett 101:241-246.

Ball GF (2000) Neuroendocrine basis of seasonal changes in vocal behavior among songbirds. In: Neural mechanisms of communication (Hauser M, Konishi M, eds), pp 213-253. Cambridge, MA: MIT.

Balthazart J, Foidart A, Wilson EM, Ball GF (1992) Immunocytochemical localization of androgen receptors in the male songbird and quail brain. J Comp Neurol 317:407-420.

Bernard DJ, Bentley GE, Balthazart J, Turek FW, Ball GF (1999) Androgen receptor, estrogen receptor alpha, and estrogen receptor beta show distinct patterns of expression in forebrain song control nuclei of European starlings. Endocrinology 140:4633-4643.

Beyer C, Feder H (1987) Sex steroids and afferent input: their roles in brain sexual differentiation. Annu Rev Physiol 49:349-364.

Bottjer SW, Johnson F (1997) Circuits, hormones, and learning: vocal behavior in songbirds. J Neurobiol 33:602-618.

Brenneman DE, Yu C, Nelson PG (1990a) Multi-determinate regulation of neuronal survival: neuropeptides, excitatory amino acids and bioelectric activity. Int J Dev Neurosci 8:371-378.

Brenneman DE, Forsythe ID, Nicol T, Nelson PG (1990b) N-methyl-Daspartate receptors influence neuronal survival in developing spinal cord cultures. Brain Res Dev Brain Res 51:63-68.

Brenowitz EA, Lent K (2000) Intracerebral implants of testosterone induce seasonal-like growth of adult avian song control circuits. Soc Neurosci Abstr 26:1268.

Brenowitz EA, Nalls B, Wingfield JC, Kroodsma DE (1991) Seasonal changes in avian song nuclei without seasonal changes in song repertoire. J Neurosci 11:1367-1374.

Brenowitz EA, Baptista LF, Lent K, Wingfield JC (1998) Seasonal plasticity of the song control system in wild Nuttall's white-crowned sparrows. J Neurobiol 34:69-82.

Clarke PGH (1985) Neuronal death during development in the isthmooptic nucleus of the chick: sustaining role of afferents from the tectum. J Comp Neurol 234:365-379.

DeVoogd T, Nottebohm F (1981) Gonadal hormones induce dendritic growth in the adult avian brain. Science 214:202-204.

DeVoogd TJ, Pyskaty DJ, Nottebohm F (1991) Lateral asymmetries and testosterone-induced changes in the gross morphology of the hypoglossal nucleus in adult canaries. J Comp Neurol 307:65-76.

DeVoogd TJ, Krebs JR, Healy SD, Purvis A (1993) Relations between song repertoire size and the volume of brain nuclei related to song: comparative evolutionary analyses amongst oscine birds. Proc R Soc Lond B Biol Sci 254:75-82. 
Dittrich F, Feng Y, Metzdorf R, Gahr M (1999) Estrogen-inducible, sex-specific expression of brain-derived neurotrophic factor mRNA in a forebrain song control nucleus of the juvenile zebra finch. Proc Natl Acad Sci USA 96:8241-8246.

Fishman RB, Breedlove SM (1992) Local perineal implants of antiandrogen block masculinization of the spinal nucleus of the bulbocavernosus. Dev Brain Res 70:283-286.

Fishman RB, Chism L, Firestone GL, Breedlove SM (1990) Evidence for androgen receptors in sexually dimorphic perineal muscles of neonatal male rats. Absence of androgen accumulation by the perineal motoneurons. J Neurobiol 21:694-704.

Furber S, Oppenheim RW, Prevette D (1987) Naturally-occurring neuron death in the ciliary ganglion of the chick embryo following removal of preganglionic input: evidence for the role of afferents in ganglion cell survival. J Neurosci 7:1816-1832.

Galli-Resta L, Ensini M, Fusco E, Gravina A, Margheritti B (1993) Afferent spontaneous electrical activity promotes the survival of target cells in the developing retinotectal system of the rat. J Neurosci 13:243-250.

Gulledge CC, Deviche P (1997) Androgen control of vocal control region volumes in a wild migratory songbird (Junco hyemalis) is region and possibly age dependent. J Neurobiol 32:391-402.

Herrmann K, Arnold AP (1991) Lesions of HVc block the developmental masculinizing effects of estradiol in the female zebra finch song system. J Neurobiol 22:29-39.

Hill KM, DeVoogd TJ (1991) Altered daylength affects dendritic structure in a song-related brain region in red-winged blackbirds. Behav Neural Biol 56:240-250.

Johnson F, Bottjer SW (1994) Afferent influences on cell death and birth during development of a cortical nucleus necessary for learned vocal behavior in zebra finches. Development 120:13-24.

Johnson F, Bottjer SW (1995) Differential estrogen accumulation among populations of projection neurons in the higher vocal center of male canaries. J Neurobiol 26:87-108.

Johnson F, Hohmann SE, DiStefano PS, Bottjer SW (1997) Neurotrophins suppress apoptosis induced by deafferentation of an avian motorcortical region. J Neurosci 17:2101-2111.

Kay JN, Hannigan P, Kelley DB (1999) Trophic effects of androgen: development and hormonal regulation of neuron number in a sexually dimorphic vocal motor nucleus. J Neurobiol 40:375-385.

Kelley DB (1986) Neuroeffectors for vocalization in Xenopus laevis: hormonal regulation of sexual dimorphism. J Neurobiol 17:231-248.

Konishi M, Akutagawa E (1981) Androgen increases protein synthesis within the avian brain vocal control system. Brain Res 222:442-446.

Levi-Montalcini R (1949) The development of the acoustico-vestibular centers in the chick embryo in the absence of afferent root fiber and of descending fiber tracts. J Comp Neurol 91:209-241.

Li XC, Jarvis ED, Alvarez-Borda B, Lim DA, Nottebohm F (2000) A relationship between behavior, neurotrophin expression, and new neuron survival. Proc Natl Acad Sci USA 97:8584-8589.

Lieberburg I, Nottebohm F (1979) High-affinity androgen binding proteins in syringeal tissues of songbirds. Gen Comp Endocrinol $37: 286-293$

Lohmann R, Gahr M (2000) Muscle-dependent and hormonedependent differentiation of the vocal control premotor nucleus robustus archistriatalis and the motor nucleus hypoglossus pars tracheosyringealis of the zebra finch. J Neurobiol 42:220-231.

Luine V, Nottebohm F, Harding C, McEwen BS (1980) Androgen affects cholinergic enzymes in syringeal motor neurons and muscle. Brain Res 192:89-107.

Luine VN, Harding CF, Bleisch WV (1983) Specificity of gonadal hormone modulation of cholinergic enzymes in the avian syrinx. Brain Res 279:339-342

Metzdorf R, Gahr M, Fusani L (1999) Distribution of aromatase, estrogen receptor, and androgen receptor mRNA in the forebrain of songbirds and nonsongbirds. J Comp Neurol 407:115-129.

Middleton J (1965) Testicular responses of house sparrows and whitecrowned sparrows to short daily photoperiods with low intensities of light. Physiol Zool 38:255-266.
Nordeen KW, Nordeen EJ, Arnold AP (1987) Estrogen accumulation in zebra finch song control nuclei: implications for sexual differentiation and adult activation of song behavior. J Neurobiol 18:569-582.

Oppenheim RW (1991) Cell death during development of the nervous system. Annu Rev Neurosci 14:453-501.

Perez J, Kelley DB (1996) Trophic effects of androgen: receptor expression and the survival of laryngeal motor neurons after axotomy. J Neurosci 16:6625-6633

Perez J, Kelley DB (1997) Androgen mitigates axotomy-induced decreases in calbindin expression in motor neurons. J Neurosci 17:7396-7403.

Rasika S, Alvarez-Buylla A, Nottebohm F (1999) BDNF mediates the effects of testosterone on the survival of new neurons in an adult brain. Neuron 22:53-62.

Rubel EW, Hyson RL, Durham D (1990) Afferent regulation of neurons in the brain stem auditory system. J Neurobiol 21:169-196.

Sansum EL, King JR (1976) Long-term effects of constant photoperiods on testicular cycles of white-crowned sparrows. Physiol Zool 49:407-416.

Schlinger BA (1997) Sex steroids and their actions on the birdsong system. J Neurobiol 33:619-631.

Smith GT, Brenowitz EA, Wingfield JC, Baptista LF (1995) Seasonal changes in song nuclei and song behavior in Gambel's white-crowned sparrows. J Neurobiol 28:114-125.

Smith GT, Brenowitz EA, Prins GS (1996) Use of PG-21 immunocytochemistry to detect androgen receptors in the songbird brain. J Histochem Cytochem 44:1075-1080.

Smith GT, Brenowitz EA, Wingfield JC (1997a) Roles of photoperiod and testosterone in seasonal plasticity of the avian song control system. J Neurobiol 32:426-442.

Smith GT, Brenowitz EA, Wingfield JC (1997b) Seasonal changes in the size of the avian song control nucleus HVC defined by multiple histological markers. J Comp Neurol 381:253-261.

Smith GT, Brenowitz EA, Beecher MD, Wingfield JC (1997c) Seasonal changes in testosterone, neural attributes of song control nuclei, and song structure in wild songbirds. J Neurosci 17:6001-6010.

Sohrabji F, Nordeen KW, Nordeen EJ (1989) Projections of androgenaccumulating neurons in a nucleus controlling avian song. Brain Res 488:253-259.

Soma KK, Hartman VN, Wingfield JC, Brenowitz EA (1998) Seasonal changes in androgen receptor immunoreactivity in the song nucleus HVc of a wild bird. J Comp Neurol 409:224-236.

Tramontin AD, Brenowitz EA (1999) A field study of seasonal neuronal incorporation into the song control system of a songbird that lacks adult song learning. J Neurobiol 40:316-326.

Tramontin AD, Brenowitz EA (2000) Seasonal plasticity in the adult brain. Trends Neurosci 23:251-258.

Tramontin AD, Smith GT, Breuner CW, Brenowitz EA (1998) Seasonal plasticity and sexual dimorphism in the avian song control system: stereological measurement of neuron density and number. J Comp Neurol 396:186-192.

Tramontin AD, Wingfield JC, Brenowitz EA (1999) Contributions of social cues and photoperiod to seasonal plasticity in the adult avian song control system. J Neurosci 19:476-483.

Tramontin AD, Hartman VN, Brenowitz EA (2000) Breeding conditions induce rapid and sequential growth in adult avian song control circuits: a model of seasonal plasticity in the brain. J Neurosci 20:854-861.

Tramontin AD, Perfito N, Wingfield JC, Brenowitz EA (2001) Seasonal growth of song control nuclei precedes seasonal reproductive development in wild adult song sparrows. Gen Comp Endocrinol, in press.

von Bartheld CS, Byers MR, Williams R, Bothwell M (1996) Anterograde transport of neurotrophins and axodendritic transfer in the developing visual system. Nature 379:830-833.

Wild JM (1997) Neural pathways for the control of birdsong production. J Neurobiol 33:653-670.

Wingfield JC, Farner DS (1978) The annual cycle of plasma irLH and steroid hormones in feral populations of the white-crowned sparrow, Zonotrichia leucophrys gambelii. Biol Reprod 19:1046-1056. 